University of Wollongong

Research Online

Australian Institute for Innovative Materials -

Papers

Australian Institute for Innovative Materials

$1-1-2015$

Integration of MnO@graphene with graphene networks towards Li-ion battery anodes

Wei Guo

Anyang Normal University

Xiu Li

Hunan University

Dickon $\mathrm{Ng}$

Chinese University of Hong Kong

Jianmin Ma

University of Wollongong

Follow this and additional works at: https://ro.uow.edu.au/aiimpapers

Part of the Engineering Commons, and the Physical Sciences and Mathematics Commons

Research Online is the open access institutional repository for the University of Wollongong. For further information contact the UOW Library: research-pubs@uow.edu.au 


\title{
Integration of MnO@graphene with graphene networks towards Li-ion battery anodes
}

\author{
Abstract \\ In this work, we have directly integrated MnO@graphene with graphene networks through the thermal \\ decomposition of a Mn-oleate complex in an Ar atmosphere at high temperatures. By introducing dual \\ protective graphene shells and networks, the as-synthesized $\mathrm{MnO} /$ graphene composites exhibited \\ superior cycling performance.

\section{Keywords} \\ integration, battery, anodes, ion, li, towards, networks, graphene, mno \\ Disciplines \\ Engineering | Physical Sciences and Mathematics

\section{Publication Details} \\ Guo, W., Li, X., Ng, D. H.L. \& Ma, J. (2015). Integration of MnO@graphene with graphene networks towards \\ Li-ion battery anodes. RSC Advances: an international journal to further the chemical sciences, 5 (117), \\ 96681-96684.
}




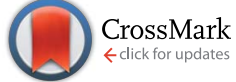

Cite this: RSC Adv., 2015, 5, 96681

Accepted 29th October 2015

DOI: $10.1039 / c 5 r a 18927 f$

www.rsc.org/advances

In this work, we have directly integrated MnOagraphene with graphene networks through the thermal decomposition of a $\mathrm{Mn}$-oleate complex in an Ar atmosphere at high temperatures. By introducing dual protective graphene shells and networks, the as-synthesized $\mathrm{MnO} / g r a p h e n e$ composites exhibited superior cycling performance.

Lithium ion batteries (LIBs) have received a great deal of success in the field of portable electronics, and have attained increasing attention in the field of transportation. ${ }^{1,2}$ With further development of these fields, higher-capacity LIBs have been required. Since transition metal oxides (TMOs) have higher theoretical capacities than carbon anodes, TMO-based anodes have been intensively studied in the past decade. ${ }^{3-12}$ Among them, MnO has a high theoretical capacity of $775 \mathrm{~mA} \mathrm{~h} \mathrm{~g}^{-1}$ (ref. 13) and is low-cost in comparison with other metals due to the abundance of manganese resources. Two intrinsic problems exist, however, for MnO-based anodes, low electrical conductivity and large volume changes during battery cycling, which lead to low coulombic efficiency and cyclability. To solve these problems, much effort has been devoted to constructing MnO@C coreshell composites, ${ }^{14-19} \mathrm{MnO} /$ graphene composites, ${ }^{20-23}$ and $\mathrm{MnO} /$ carbon composites, ${ }^{24-29}$ which could potentially accommodate the volume changes. Core-shell structures hardly suppress the volume changes in anodes during battery cycling. TMO/ graphene composites have been suggested as advanced anodes, ${ }^{20-23}$ since elastic graphene sheets can accommodate the volume changes during battery cycling, although they usually

${ }^{a}$ College of Chemistry and Chemical Engineering, Anyang Normal University, Anyang 455000, China

${ }^{b}$ Key Laboratory for Micro-/Nano-Optoelectronic Devices of the Ministry of Education, School of Physics and Electronics, Hunan University, Changsha 410082, P. R. China. E-mail: nanoelechem@hnu.edu.cn

'Department of Physics, The Chinese University of Hong Kong, Hongkong, P. R. China. E-mail:dng@phy.cuhk.edu.hk

${ }^{d}$ Institute for Superconducting and Electronic Materials, University of Wollongong, Wollongong 2500, Australia

$\dagger$ Electronic supplementary information (ESI) available. See DOI: $10.1039 / \mathrm{c} 5 \mathrm{ra} 18927 \mathrm{f}$ show poor electrical conductivity, because there are junction contact resistances and structural defects in ultrathin nanosheets derived from the chemical synthesis process. ${ }^{30}$ Thus, it is still a big challenge to construct MnO-based anodes that address both the electrical conductivity and the volume change problems.

In this work, we have successfully developed a one-step synthetic route to prepare MnO@graphene with graphene networks (MnO@G/GNs), just simply through the thermal decomposition of Mn-oleate complex in $\mathrm{Ar}$ atmosphere at high temperatures. The as-synthesized MnO@G/GNs have the dual functional effect of ultrathin graphite towards improving conductivity and accommodating the volume changes, as reported for the example of Ge-based anodes by Guo's group. ${ }^{31}$ The optimized material shows a discharge capacity of $820 \mathrm{~mA} \mathrm{~h}$ $\mathrm{g}^{-1}$ after 50 cycles at a specific current of $50 \mathrm{~mA} \mathrm{~g}^{-1}$, and even $500 \mathrm{~mA} \mathrm{~h} \mathrm{~g}{ }^{-1}$ at a specific current of $1600 \mathrm{~mA} \mathrm{~g}^{-1}$.

The structural characterization of the as-synthesized MnO@G/GNs samples was conducted by X-ray diffraction (XRD), Raman spectroscopy, X-ray photoelectron spectroscopy (XPS), and thermogravimetric analysis (TGA). Fig. 1a presents the XRD patterns of the as-prepared MnO@G/GNs-700, MnO@G/GNs-850, and MnO@G/GNs-1000, which can be well indexed to cubic phase MnO (JPDS 78-0424). ${ }^{32}$ As shown in Fig. $1 \mathrm{~b}$ and $\mathrm{S} 1$ in the ESI, $\dagger$ all the Raman spectra of the asprepared MnO@G/GNs-700, MnO@G/GNs-850, and MnO@G/ GNs-1000 show four remarkable peaks centered at around $646,1340,1589$, and $2643 \mathrm{~cm}^{-1}$, respectively. Among them, the peaks centered at around 1340 and $1589 \mathrm{~cm}^{-1}$ can be assigned to the defects or disorder (D band) and the $\mathrm{E}_{2 \mathrm{~g}}$ mode ( $\mathrm{G}$ band), respectively, while the one at $2643 \mathrm{~cm}^{-1}$ can be assigned to the graphene 2D peak. ${ }^{33}$ As shown in the XPS spectra (Fig. 1c and S2 $\dagger$ ), the signals for the elements manganese, oxygen, and carbon are generated from the $\mathrm{MnO}$ and the graphene, respectively. The four signals at $641.2,652.8,532.4$, and $284.6 \mathrm{eV}$ are assigned to $\mathrm{Mn} 2 \mathrm{p}_{3 / 2}, \mathrm{Mn} 2 \mathrm{p}_{1 / 2}, \mathrm{O} 1 \mathrm{~s}$, and C 1s, respectively. ${ }^{34}$ According to the TGA results, the carbon content for the asprepared MnO@G/GNs-700, MnO@G/GNs-850, and MnO@G/ 

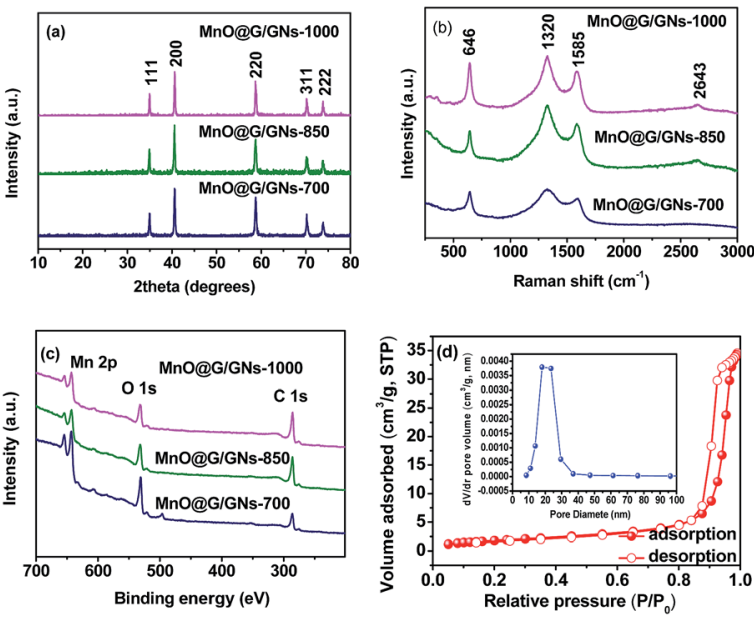

Fig. 1 (a) XRD patterns, (b) Raman spectra, and (c) XPS spectra of MnO@G/GNs-700, MnOaG/GNs-850, and MnO@G/GNs-1000; (d) nitrogen absorption-desorption isotherms and pore size distribution (inset) of MnO@G/GNs-850.

GNs-1000, are evaluated to be about $13.2 \mathrm{wt} \%, 12.8 \%$ and 9.9\%, respectively. Fig. $\mathrm{S} 3 \uparrow$ and $1 \mathrm{~d}$ show the $\mathrm{N}_{2}$ adsorption-desorption isotherms and their corresponding pore size distribution curves for the as-prepared MnO@G/GNs. The Brunauer-EmmettTeller (BET) specific surface areas for MnO@G/GNs-700, MnO@G/ GNs-850, and MnO@G/GNs-1000 are 21.6, 8.9, and $7.1 \mathrm{~m}^{2} \mathrm{~g}^{-1}$, respectively. The pore size distributions (insets of http:// www.nature.com/srep/2014/140306/srep04229/full/srep04229.html Fig. S3† and 1d) suggest that the MnO@G/GNs samples have numerous mesopores, which are expected to facilitate access of the electrolyte to the internal active materials.

The morphology of the as-synthesized MnO@G/GNs samples was characterized by scanning electron microscopy (SEM) and transition electron microscopy (TEM), respectively. Fig. 2a-c show SEM images of the as-prepared MnO@G/GNs-700, MnO@G/GNs-850, and MnO@G/GNs-1000, respectively. In

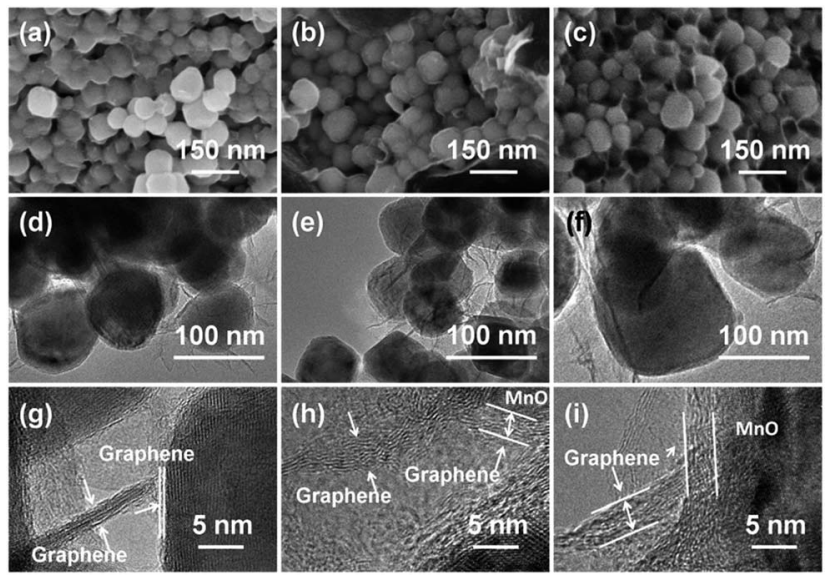

Fig. 2 (a-c) SEM images of MnOaG/GNs-700, MnO@G/GNs-850, and MnO@G/GNs-1000; (d-f) TEM images of MnO@G/GNs-700, $\mathrm{MnO} @ \mathrm{G} / \mathrm{GNs}-850$, and $\mathrm{MnO}(\mathrm{GG} / \mathrm{GNs}-1000$; (g-i) HR-TEM images of $\mathrm{MnO} @ \mathrm{G} / \mathrm{GNs}-700, \mathrm{MnO} @ \mathrm{G} / \mathrm{GNs}-850$, and MnO@G/GNs-1000.
Fig. 2a-c, one can see that all the samples are composed of nanoparticles, linked with ultrathin nanosheets. In the TEM images (Fig. 2d-f), the nanoparticles are embedded in ultrathin nanosheets for the three samples. In addition, coating layers can be observed on the surfaces of the three samples in the high-magnification TEM (HR-TEM) images (Fig. 2g-i). Both the coating thickness and the thickness of the graphene are limited to within ten layers.

The formation of $\mathrm{MnO} @ \mathrm{G} / \mathrm{GNs}$ can be well explained as due to the growth of MnO via the thermal decomposition of Mnoleate complex and the growth of graphene. MnO is easily formed at high temperatures due to the thermal decomposition of the Mn-oleate complex, which is similar to the formation of MnO nanocrystals in solutions at high temperatures. ${ }^{35-37}$ The formation of graphene is associated with the carbonization of oleate anions at high temperatures. The organic moieties could be easily formed into sheet-like structure due to the twodimensional characteristics of carbon. ${ }^{38}$ Thus, the graphene could be formed. In addition, due to the formation of $\mathrm{MnO}$ nanocrystals, the carbon coating layer of $\mathrm{MnO}$ nanocrystals could be formed at the same time. In our previous works, oleic acid was used as the carbon source for the coating layer on the surface of nanoparticles ( $\mathrm{TiN}, \mathrm{NiO}$, and $\mathrm{Nb}_{2} \mathrm{O}_{5}$ ). ${ }^{39-41}$ Interestingly, graphene was formed as the coating layer in the composite, which is different from our previous work. This might be associated with the amount of oleic acid and the kinds of metal ions. MnO@G/GNs are expected to have excellent electrochemical performance when used as anode materials for LIBs due to the two types of protective graphene layers, which improve conductivity and accommodate its volume changes, thus leading to enhanced electrochemical lithium-storage performance.

The electrochemical performance of the MnO@G/GNs was evaluated by cyclic voltammetry (CV) and galvanostatic discharge/charge tests. Fig. 3a shows the CV curves of the MnO@G/GNs-850 electrode for the initial three cycles at a scan rate of $0.1 \mathrm{mV} \mathrm{s}^{-1}$ in the voltage range of $0.01-3 \mathrm{~V} v s$. Li. In the first cycle, the cathodic peak at $\sim 0.15 \mathrm{~V}$, which shifts to $0.42 \mathrm{~V}$ in the subsequent cycles, was ascribed to the complete reduction of $\mathrm{Mn}^{2+}$ to $\mathrm{MnO}$. The positive shift of the cathodic peak was due to the improved kinetics of the MnO@G/GNs-850 electrode. The oxidation peak at $\sim 1.32 \mathrm{~V}$ was attributed to the oxidation of $\mathrm{Mn}^{0}$ to $\mathrm{Mn}^{2+}$ in the cathodic process. ${ }^{36}$ Fig. $3 \mathrm{~b}$ shows the chargedischarge voltage profiles of the MnO@G/GNs electrodes at a current density of $50 \mathrm{~mA} \mathrm{~g}^{-1}$ within a voltage window of $0.01-$ $3.0 \mathrm{~V}\left(v s . \mathrm{Li}^{+} / \mathrm{Li}\right)$ for the initial three cycles. As shown in Fig. 3b, a plateau at around 1.25 V for MnO@G/GNs-850 is observed in the charge curves, while the corresponding discharge plateau is located at $0.5 \mathrm{~V}$. This is similar to the reported literature. Fig. 3c and $\mathrm{S} 4 \uparrow$ show the cycling performances of the as-prepared $\mathrm{MnO} @ \mathrm{G} / \mathrm{GNs}$ at $50 \mathrm{~mA} \mathrm{~g}^{-1}$ in the voltage range of $0.01-3.0 \mathrm{~V}$. The discharge capacity for $\mathrm{MnO} @ G / G N s-850$ significantly decreases from $1040 \mathrm{~mA} \mathrm{~h} \mathrm{~g}^{-1}$ for the $1^{\text {st }}$ cycle to $845 \mathrm{~mA} \mathrm{~h} \mathrm{~g}^{-1}$ for the $2^{\text {nd }}$ cycle, and then stabilizes at above $830 \mathrm{~mA} \mathrm{~h} \mathrm{~g}^{-1}$, respectively. The capacities for $\mathrm{MnO} @ \mathrm{G} / \mathrm{GNs}-700$ and $\mathrm{MnO} @ \mathrm{G} /$ GNs-1000 obviously decrease, however, to 634 and $690 \mathrm{~mA} \mathrm{~h} \mathrm{~g}^{-1}$ after 50 cycles. The coulombic efficiency of MnO@G/GNs 

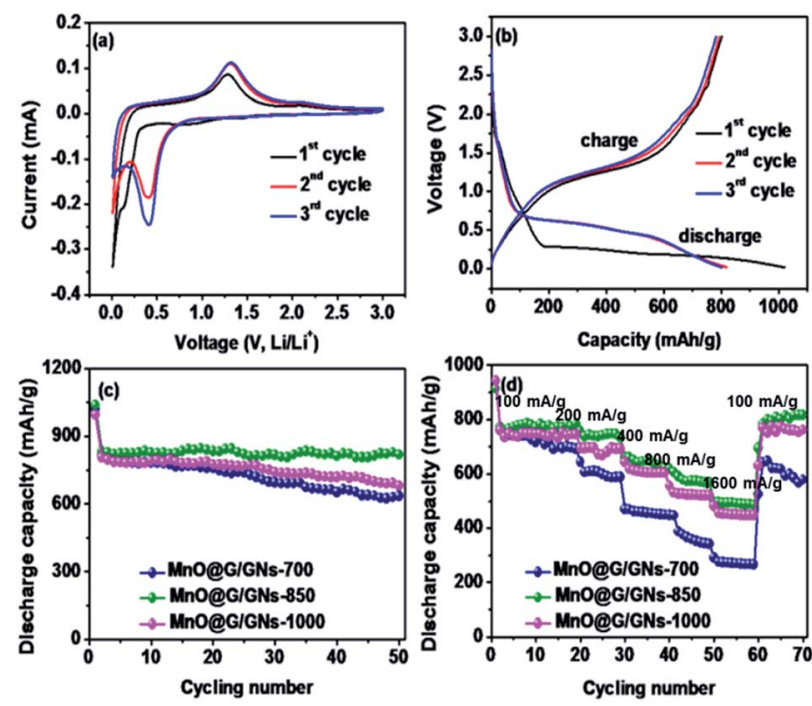

Fig. 3 (a) CV curves and (b) charge/discharge curves for the first 3 cycles of $\mathrm{MnO} @ \mathrm{G} / \mathrm{GNs}-850$; (c) cycling performance at a current density of $50 \mathrm{~mA} \mathrm{~g}^{-1}$ and (d) rate performance of MnOaG/GNs-700, $\mathrm{MnO}(\mathrm{G} / \mathrm{GNs}-850$, and MnO@G/GNs-1000.

stabilizes at about $100 \%$, except for the $1^{\text {st }}$ cycle. Fig. 3d shows the rate capability of the as-prepared MnO@G/GNs, which indicates a decreasing trend in capacity with increasing current rate. Compared with MnO@G/GNs-700 and MnO@G/GNs-1000, MnO@G/GNs-850 exhibits higher discharge capacities at the same current densities. When the current density increases
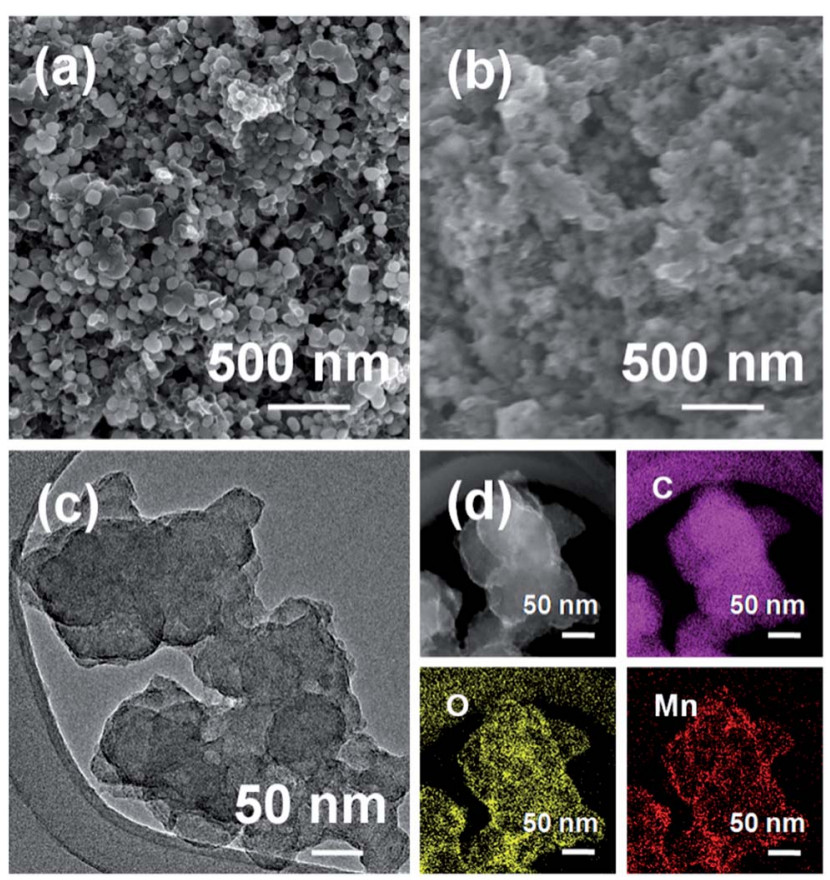

Fig. 4 SEM images of electrodes: (a) fresh MnO@G/GNs-850 and (b) MnO@G/GNs-850 after 50 cycles; (c) TEM image of MnO@G/GNs850 after 50 cycles; (d) high-angle annular dark field scanning TEM (HAADF-STEM) image, C elemental map, O elemental map, and Mn elemental map. from $100 \mathrm{~mA} \mathrm{~g}^{-1}$ to $200,400,800$, and $1600 \mathrm{~mA} \mathrm{~g}^{-1}$, the capacity of MnO@G/GNs-850 drops from $783 \mathrm{~mA} \mathrm{~h} \mathrm{~g}^{-1}$ to $742,645,576$, and $493 \mathrm{~mA} \mathrm{~h} \mathrm{~g}^{-1}$, respectively. When the current density goes back to $100 \mathrm{~mA} \mathrm{~g}^{-1}$, the specific storage capacity of MnO@G/

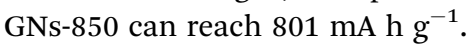

The morphology of the MnO@G/GNs-700 electrode over 50 discharge/charge cycles was studied. Compared to the fresh MnO@G/GNs-850 electrode (Fig. 4a), the electrode after the $50^{\text {th }}$ cycle has completely collapsed due to the instability of $\mathrm{MnO}$ structure, as shown in Fig. $4 \mathrm{~b}$ and c. The ultrafine MnO nanoparticles were dispersed on the graphene nanosheets after 50 discharge/charge cycles, as observed in the elemental mapping results (Fig. 4d). Both the small size of the MnO nanoparticles and the electronically conductive graphene facilitate lithiumion and electron transfer and improve the rate capability with their synergistic effects. The MnO nanoparticles with small size have smaller volume changes. Graphene nanosheets can effectively buffer the volume changes and inhibit the aggregation of MnO during the lithium-ion insertion/exaction. Additionally, the integrated electrode structure facilitates the improved electrical conductivity, structural flexibility, and chemical stability of the hybrid electrode, leading to significant enhancement of the utilization efficiency of the active manganese oxide and the discharge/charge capacity at large current densities.

\section{Conclusions}

In conclusion, we have successfully fabricated $\mathrm{MnO} / \mathrm{G} / \mathrm{GNs}$ composites through the thermal decomposition of Mn-oleate complex in Ar atmosphere at high temperatures. By introducing dual protective graphene shells and networks, we improved the battery cycling performance of the as-synthesized MnO@G/GNs over those of previous composites. Such a simple strategy provides a simple and versatile route to integrate metal oxides and graphene in composites to form high-capacity electrode materials with excellent cycling properties.

\section{Acknowledgements}

This work was supported by the National Natural Science Foundation of China (Grant No. 51302079). We also thank Dr Tania Silver from the Institute for Superconducting and Electronic Materials (University of Wollongong) for revising our manuscript.

\section{Notes and references}

1 J. B. Goodenough, J. Solid State Electrochem., 2012, 16, 20192029.

2 C. Wang, H. Wu, Z. Chen, M. T. McDowell, Y. Cui and Z. N. Bao, Nat. Chem., 2013, 5, 1042-1048.

3 Y. Cai, X. Li, L. Wang, H. Y. Gao, Y. N. Zhao and J. M. Ma, J. Mater. Chem. A, 2015, 3, 1396-1399.

4 Y. J. Chen, J. M. Ma, Q. H. Li and T. H. Wang, Nanoscale, 2013, 5, 3262-3265.

5 J. M. Ma and A. Manthiram, RSC Adv., 2012, 2, 3187-3189. 
6 J. M. Ma, J. B. Lian, X. C. Duan, X. D. Liu and W. J. Zheng, J. Phys. Chem. C, 2010, 114, 10671-10676.

7 X. Li, J. T. Xu, L. Mei, Z. J. Zhang, C. Y. Cui, H. K. Liu, J. M. Ma and S. X. Dou, J. Mater. Chem. A, 2015, 3, 3257-3260.

8 Y. H. Xu, G. Q. Jian, M. R. Zachariah and C. S. Wang, J. Mater. Chem. A, 2013, 1, 15486-15490.

9 W.-M. Zhang, X.-L. Wu, J.-S. Hu, Y.-G. Guo and L.-J. Wan, Adv. Funct. Mater., 2008, 18, 3941-3946.

10 X. Yun, Y. Ran, B. Yuan, X. F. Wu, M. Dunwell, Q. L. Lin, L. Fei, S. G. Deng, P. Andersen, D. H. Wang and H. M. Luo, J. Phys. Chem. Lett., 2012, 3, 309-314.

11 A. Caballero, L. Hernán and J. Morales, Energy Fuels, 2013, 27, 5545-5551.

12 J. Lin, Z. W. Peng, C. S. Xiang, G. D. Ruan, Z. Yan, D. Natelson and J. M. Tour, ACS Nano, 2013, 7, 6001-6006.

13 Y. Liu, X. Zhao, F. Li and D. Xia, Electrochim. Acta, 2011, 56, 6448-6452.

14 S. B. Wang, Y. B. Ren, G. R. Liu, Y. L. Xing and S. C. Zhang, Nanoscale, 2014, 6, 3508-3512.

15 T. Qiu, J. Wang, Y. L. Lu and W. S. Yang, RSC Adv., 2014, 4, 23027-23035.

16 L. W. Su, Y. R. Zhong, J. P. Wei and Z. Zhou, RSC Adv., 2013, 3, 9035-9041.

17 S. Shanmugam and A. Gedanken, J. Phys. Chem. B, 2006, 110, 24486-24491.

18 B. Sun, Z. X. Chen, H.-S. Kim, H. Ahn and G. X. Wang, J. Power Sources, 2011, 196, 3346-3349.

19 X. Zhang, Z. Xing, L. L. Wang, Y. C. Zhu, Q. W. Li, J. W. Liang, Y. Yu, T. Huang, K. B. Tang, Y. T. Qian and X. Y. Shen, J. Mater. Chem., 2012, 22, 17864-17869.

20 J. Zang, H. Qian, Z. K. Wei, Y. Cao, M. S. Zheng and Q. F. Dong, Electrochim. Acta, 2014, 118, 112-117.

21 S. Zhang, L. X. Zhu, H. H. Song, X. H. Chen and J. S. Zhou, Nano Energy, 2014, 10, 172-180.

22 Y. M. Sun, X. L. Hu, W. Luo, F. F. Xia and Y. H. Huang, Adv. Funct. Mater., 2013, 23, 2436-2444.

23 Q. Y. Liao, N. Li, H. Cui and C. X. Wang, J. Mater. Chem. A, 2013, 1, 13715-13720.

24 W. J. Zhu, H. Huang, W. K. Zhang, X. Y. Tao, Y. P. Gan, Y. Xia, H. Yang and X. Z. Guo, Electrochim. Acta, 2015, 152, 286-293.
25 K. Su, C. Wang, H. G. Nie, Y. Guan, F. Liu and J. T. Chen, J. Mater. Chem. A, 2014, 2, 10000-10006.

26 Y. Xia, Z. Xiao, X. Dou, H. Huang, X. H. Lu, R. J. Yan, Y. P. Gan, W. J. Zhu, J. P. Tu, W. K. Zhang and X. Y. Tao, ACS Nano, 2013, 7, 7083-7092.

27 W. Luo, X. L. Hu, Y. M. Sun and Y. H. Huang, ACS Appl. Mater. Interfaces, 2013, 5, 1997-2003.

28 Y. M. Liu, X. Y. Zhao, F. Li and D. G. Xia, Electrochim. Acta, 2011, 56, 6448-6452.

29 Y. L. Ding, C. Y. Wu, H. M. Yu, J. Xie, G. S. Cao, T. J. Zhu, X. B. Zhao and Y. W. Zeng, Electrochim. Acta, 2011, 56, 5844-5848.

30 Z. P. Chen, W. C. Ren, L. B. Gao, B. L. Liu, S. F. Pei and H.-M. Cheng, Nat. Mater., 2011, 10, 424-428.

31 D.-J. Xue, S. Xin, Y. Yan, K.-C. Jiang, Y.-X. Yin, Y.-G. Guo and L.-J. Wan, J. Am. Chem. Soc., 2012, 134, 2512-2515.

32 J. Park, K. An, Y. Hwang, J.-G. Park, H.-J. Noh, J.-Y. Kim, J.-H. Park, N.-M. Hwang and T. Hyeon, Nat. Mater., 2014, 3, 891-895.

33 L. M. Malard, M. A. Piment, G. Dresselhaus and M. S. Dresselhaus, Phys. Rep., 2009, 473, 51-87.

34 B. Liu, X. L. Hu, H. H. Xu, W. Luo, Y. M. Sun and Y. H. Huang, Sci. Rep., 2014, 4, 4229.

35 A. Puglisi, S. Mondini, S. Cenedese, A. M. Ferretti, N. Santo and A. Ponti, Chem. Mater., 2010, 22, 2804-2813.

36 Q. Li, J. Wang, Y. J. He, W. Liu and X. H. Qiu, Cryst. Growth Des., 2009, 9, 3100-3103.

37 K. An, M. Park, J. H. Yu, H. B. Na, N. Lee, J. Park, S. H. Choi, I. C. Song, W. K. Moon and T. Hyeon, Eur. J. Inorg. Chem., 2012, 2148-2155.

38 L. Wang, S. Dou, J. T. Xu, H. K. Liu, S. Y. Wang, J. M. Ma and S. X. Dou, Chem. Commun., 2015, 51, 11791-11794.

39 D. N. Lei, T. Yang, B. H. Qu, J. M. Ma, Q. H. Li, L. B. Chen and T. H. Wang, Sustainable Energy, 2014, 2, 1-4.

40 G. Zhou, J. M. Ma and L. B. Chen, Electrochim. Acta, 2014, 133, 93-99.

41 L. Wang, B. Y. Ruan, J. T. Xu, H. K. Liu and J. M. Ma, RSC Adv., 2015, 5, 36104-36107. 